\title{
Associations between DSM-IV mental disorders and diabetes mellitus: a role for impulse control disorders and depression
}

\author{
Peter de Jonge - Jordi Alonso • Dan J. Stein • Andrzej Kiejna • Sergio Aguilar-Gaxiola • \\ Maria Carmen Viana - Zhaorui Liu • Siobhan O'Neill • Ronny Bruffaerts • \\ Jose Miguel Caldas-de-Almeida • Jean-Pierre Lepine • Herbert Matschinger • \\ Daphna Levinson • Giovanni de Girolamo • Akira Fukao • Brendan Bunting • \\ Josep Maria Haro • Jose A. Posada-Villa • Ali Obaid Al-Hamzawi • \\ Maria Elena Medina-Mora • Marina Piazza • Chiyi Hu • Carmen Sasu • \\ Carmen C. W. Lim • Ronald C. Kessler • Kate M. Scott
}

Received: 3 October 2013 / Accepted: 16 December 2013 / Published online: 2 February 2014

(C) Springer-Verlag Berlin Heidelberg 2014

\begin{abstract}
Aims/hypothesis No studies have evaluated whether the frequently observed associations between depression and diabetes could reflect the presence of comorbid psychiatric conditions and their associations with diabetes. We therefore
\end{abstract}

Electronic supplementary material The online version of this article (doi:10.1007/s00125-013-3157-9) contains peer-reviewed but unedited supplementary material, which is available to authorised users.

P. de Jonge $(\bowtie)$

Interdisciplinary Center Psychopathology and Emotion Regulation, University Medical Center Groningen, University of Groningen, PO 9700 MB Groningen, The Netherlands

e-mail: peter.de.jonge@umcg.nl

J. Alonso

CIBER en Epidemiología y Salud Pública (CIBERESP), Spain

URL: www.ciberesp.es

\section{J. Stein}

Department of Psychiatry and Mental Health, University of Cape

Town, Cape Town, South Africa

\section{A. Kiejna}

Department of Psychiatry, Wroclaw Medical University,

Wroclaw, Poland

\section{S. Aguilar-Gaxiola}

Center for Reducing Health Disparities, School of Medicine,

Sacramento, CA, USA

\section{C. Viana}

Department of Social Medicine, Federal University of Espírito Santo (UFES), Vitória, Espírito Santo, Brazil

\section{Z. Liu}

Institute of Mental Health, Peking University, Beijing, China examined the associations between a wide range of preexisting Diagnostic Statistical Manual, 4th edition (DSMIV) mental disorders with self-reported diagnosis of diabetes. Methods We performed a series of cross-sectional face-toface household surveys of community-dwelling adults

S. O’Neill

School of Psychology, University of Ulster, Londonderry, UK

R. Bruffaerts

University Hospital Gasthuisberg, Leuven, Belgium

J. M. Caldas-de-Almeida

Chronic Diseases Research Center (CEDOC) and Department of Mental Health, Faculdade de Ciências Médicas, Universidade Nova de Lisboa, Lisbon, Portugal

J.-P. Lepine

Hôpital Lariboisiére Fernand Widal, Paris, France

H. Matschinger

Clinic of Psychiatry, University of Leipzig, Leipzig, Germany

D. Levinson

Mental Health Services, Ministry of Health, Jerusalem, Israel

G. de Girolamo

Health Services Research Unit, Institut Municipal d'Investigació Mèdica (IMIM-Hospital del Mar), IRCCS Centro S. Giovanni di Dio Fatebenefratelli, Bologna, Italy

A. Fukao

Department of Public Health, Yamagata University School of Medicine, Yamagata, Japan 
$(n=52,095)$ in 19 countries. The World Health Organization Composite International Diagnostic Interview retrospectively assessed lifetime prevalence and age at onset of 16 DSM-IV mental disorders. Diabetes was indicated by self-report of physician's diagnosis together with its timing. We analysed the associations between all mental disorders and diabetes, without and with comorbidity adjustment.

Results We identified 2,580 cases of adult-onset diabetes mellitus $(21$ years +$)$. Although all 16 DSM-IV disorders were associated with diabetes diagnosis in bivariate models, only depression (OR 1.3; 95\% CI 1.1, 1.5), intermittent explosive disorder (OR 1.6; 95\% CI 1.1, 2.1), binge eating disorder (OR 2.6; 95\% CI 1.7, 4.0) and bulimia nervosa (OR 2.1; 95\% CI 1.3,3.4) remained after comorbidity adjustment.

Conclusions/interpretation Depression and impulse control disorders (eating disorders in particular) were significantly associated with diabetes diagnosis after comorbidity adjustment. These findings support the focus on depression as having a role in diabetes onset, but suggest that this focus may be extended towards impulse control disorders. Acknowledging the comorbidity of mental disorders is important in determining the associations between mental disorders and subsequent diabetes.

Keywords Comorbidity · Depression · Epidemiology · Impulse control disorders $\cdot$ Mental disorders

\section{Abbreviations \\ CIDI Composite International Diagnostic Interview \\ DSM-IV Diagnostic Statistical Manual, 4th edition \\ WMH World Mental Health}

\author{
B. Bunting \\ Psychology Research Institute, University of Ulster, \\ Londonderry, UK \\ J. M. Haro \\ Parc Sanitari Sant Joan de Déu, CIBERSAM, \\ University of Barcelona, Barcelona, Spain \\ J. A. Posada-Villa \\ Instituto Colombiano del Sistema Nervioso, Bogota D.C., Colombia
}

A. O. Al-Hamzawi

Al-Qadisiya University, College of Medicine,

Diwania Governorate, Iraq

M. E. Medina-Mora

National Institute of Psychiatry, Calzada Mexico Xochimilco,

Mexico City, Mexico

\section{Piazza}

Facultad de Salud Publica y Administración (FASPA), Universidad

Peruana Cayetano Heredia, Lima, Peru

\section{Introduction}

Many studies have reported sequential associations between mood disorders and diabetes mellitus and these have been summarised in a series of meta-analyses [1-4]. These analyses have clarified several points: (1) depression and diabetes frequently co-occur; (2) the presence of depression increases the risk of future diabetes and (3) diabetes increases the risk of subsequent depression. Moreover, the comorbidity of depression and diabetes has been found to be particularly harmful in terms of cardiovascular events, cardiac mortality and mortality in general [5-8].

Most attention in this body of literature has been directed to the possibility that depression serves as a risk factor for diabetes, as depression is potentially modifiable and its treatment might translate into a decreased risk of diabetes onset [9]. This is theoretically plausible as the typical age of onset of depression is considerably lower than the typical age of diabetes onset. A recent report of the World Mental Health (WMH) surveys concluded that the mean age of depression onset is about 25 years [10], while for type 2 diabetes mellitus - by far the most common form of diabetes - mean age of onset is $>45$ years [11]. Moreover, several physiological and behavioural mechanisms have been proposed to explain this possible link [12-14].

Most of the available evidence has been derived from observational studies. However, two limitations of the existing observational studies significantly hamper progress in our understanding of the depression-diabetes association. First, although some recent studies were performed in Asia (e.g. [14]), the literature is dominated by study samples from the USA and Europe [15-17]. This poses a problem as prevalence

C. $\mathrm{Hu}$

Shenzhen Institute of Mental Health and Shenzhen Kangning

Hospital, Shenzhen, Guangdong Province,

People's Republic of China

\section{Sasu}

National School of Public Health, Management and Professional Development, Bucharest, Romania

C. C. W. Lim $\cdot$ K. M. Scott

Department of Psychological Medicine, University of Otago, Dunedin, New Zealand

R. C. Kessler

Department of Healthcare Policy, Harvard Medical School, Boston, MA, USA 
rates of depression and diabetes vary substantially across nations and level of national development [14]. Second, and more importantly, it is unclear whether the depression-diabetes association may be explained by the presence of other mental disorders. Depression frequently co-occurs not only with anxiety disorders but also with many of the other Diagnostic Statistical Manual, 4th edition (DSM-IV) mental disorders such as eating disorders and alcohol abuse [18-20]. For instance, the lifetime rate of major depressive disorder in individuals with eating disorders is as high as $50-75 \%$ [21], although some heterogeneity in findings has been reported [22]. As the literature has focused exclusively on depression, it remains possible for a person to develop an eating disorder, become depressed later on, and in the end develop diabetes mellitus. Targeting the eating disorder in this case will theoretically be a far more promising approach than focusing solely on depression.

Previous studies were unable to address these problems as they were mostly based on a single country, and in particular did not collect reliable data on the presence of mental disorders other than depression. We therefore conducted the present study within the framework of the WMH surveys $[23,24]$ to examine the associations between a wide range of DSM-IV mental disorders and diabetes diagnosis. This approach enabled us to investigate the association between first onset of mood, anxiety, impulse control (including eating disorders) and substance use disorders with diabetes diagnosis in a large international sample. Moreover by conducting analyses without and with adjustment for mental disorder comorbidity we evaluated whether the exclusive focus on depression as a risk factor for diabetes onset is warranted.

\section{Methods}

Samples and procedures This study uses data from 19 of the WMH surveys: Colombia, Mexico, Peru, USA, Shenzhen (China), Japan, New Zealand, Belgium, France, Germany, Italy, the Netherlands, Romania, Spain, Portugal, Israel, Iraq, Northern Ireland and Poland (see Table 1). Using stratified multi-stage clustered area probability sampling we selected adult respondents $(18$ years + ) in most WMH survey countries. Most of the surveys were based on nationally representative household samples except for those from Colombia, Mexico and Shenzhen, which were based on nationally representative household samples in urbanised areas.

In most countries, internal subsampling was used to reduce respondent burden and average interview time by dividing the interview into two parts. All respondents completed part 1, including the core diagnostic assessment of most mental disorders. Part 2, which assessed physical conditions and a range of other information related to the aims of the survey, was administered to all part 1 respondents who met lifetime criteria for any mental disorder and also to a probability sample of other respondents. Part 2 respondents were weighted by the inverse of their probability of selection for part 2 of the interview to adjust for differential sampling. Analyses in this paper are based on the weighted part 2 subsample $(n=52,095)$. Additional weights were used to adjust for differential probabilities of selection within households, adjusting for nonresponse, and matching the samples to population sociodemographic distributions. Measures taken to ensure interviewer and data accuracy and cross-national consistency are described elsewhere [22, 23] All respondents provided informed consent and procedures for protecting respondents were approved and monitored for compliance by the Institutional Review Boards in each country (see [22] for details).

Data collection: mental disorders All surveys used the WMH version of the WHO Composite International Diagnostic Interview (CIDI 3.0) [23], a fully structured interview conducted by trained laypersons, to assess lifetime history of most of the mental disorders. All interviewers were trained in the use of the CIDI by a WHO-authorised training and reference centre. It should be noted, however, that not all disorders were assessed (e.g. the CIDI interview does not include schizophrenia). Disorders covered by the CIDI were assessed using the definitions and criteria of the DSM-IV. A total of 16 mental disorders were used for the present analyses. Anorexia nervosa was excluded due to too low prevalence in the data set to warrant reliable analyses. The mental disorders evaluated in this paper include anxiety disorders (panic disorder, generalised anxiety disorder, social phobia, specific phobia, agoraphobia without panic, post-traumatic stress disorder, obsessive-compulsive disorder); mood disorders (major depressive disorder/dysthymia, bipolar disorder [broad]); impulse control disorders (intermittent explosive disorder, bulimia nervosa, binge eating disorder) and substance use disorders (alcohol abuse and dependence, drug abuse and dependence). Depression and dysthymia were analysed together as CIDI validation studies indicated that a clinical diagnosis of dysthymia was not well-captured by the CIDI interview.

CIDI organic exclusion rules were applied in making diagnoses, while no hierarchical rules were used except with respect to the two eating disorders. Clinical reappraisal studies conducted in some of the WMH survey countries indicate that lifetime diagnoses of anxiety, mood and substance use disorders based on the CIDI have generally good concordance with diagnoses based on blinded clinical interviews [25].

Data collection: diabetes mellitus In a series of questions adapted from the US Health Interview Survey, respondents were asked about the lifetime presence of selected chronic conditions. Respondents were asked: "Did a doctor or other health professional ever tell you that you had any of the following illnesses....diabetes?" If respondents endorsed this 
Table 1 Characteristics of WMH survey samples and number of persons with diabetes

\begin{tabular}{|c|c|c|c|c|c|c|c|c|c|}
\hline Country & Field date & $\begin{array}{l}\text { Age range } \\
\text { (years) }\end{array}$ & $\begin{array}{l}\text { Mean age } \\
\text { (years) }\end{array}$ & \% Women & Part $1(n)$ & Part $2(n)$ & $\begin{array}{l}\text { Response } \\
\text { rate }(\%)\end{array}$ & $\begin{array}{l}\text { Diabetes } \\
(n)\end{array}$ & $\begin{array}{l}\text { Diabetes } \\
(\%)\end{array}$ \\
\hline \multicolumn{10}{|l|}{ Americas } \\
\hline Colombia & 2003 & $18-65$ & 36.7 & 62.8 & 4,426 & 2,381 & 87.7 & 54 & 2.9 \\
\hline Mexico & 2001-2002 & $18-65$ & 36.0 & 63.9 & 5,782 & 2,362 & 76.6 & 125 & 4.8 \\
\hline USA & $2002-2003$ & $18+$ & 43.4 & 58.2 & 9,282 & 5,692 & 70.9 & 373 & 7.3 \\
\hline Peru & 2005-2006 & $18-65$ & 36.8 & 55.8 & 3,930 & 1,801 & 90.2 & 32 & 2.0 \\
\hline \multicolumn{10}{|l|}{ Asia and South Pacific } \\
\hline Japan & $2002-2006$ & $20+$ & 52.5 & 56.4 & 4,129 & 1,682 & 55.1 & 99 & 5.0 \\
\hline Shenzhen (People's Republic of China) & 2006-2007 & $18+$ & 31.6 & 49.3 & 7,132 & 2,475 & 80.0 & 33 & 0.8 \\
\hline New Zealand & 2003-2004 & $18+$ & 43.8 & 59.6 & 12,790 & 7,312 & 73.3 & 401 & 4.8 \\
\hline \multicolumn{10}{|l|}{ Europe } \\
\hline Belgium & $2001-2002$ & $18+$ & 47.6 & 55.3 & 2,419 & 1,043 & 50.6 & 40 & 3.7 \\
\hline France & $2001-2002$ & $18+$ & 46.1 & 59.3 & 2,894 & 1,436 & 45.9 & 52 & 4.1 \\
\hline Germany & $2002-2003$ & $18+$ & 47.7 & 57.6 & 3,555 & 1,323 & 57.8 & 63 & 4.8 \\
\hline Italy & $2001-2002$ & $18+$ & 47.0 & 54.5 & 4,712 & 1,779 & 71.3 & 59 & 3.4 \\
\hline The Netherlands & $2002-2003$ & $18+$ & 47.3 & 58.9 & 2,372 & 1,094 & 56.4 & 61 & 7.2 \\
\hline Spain & 2001-2002 & $18+$ & 49.6 & 61.4 & 5,473 & 2,121 & 78.6 & 140 & 5.8 \\
\hline Northern Ireland & 2004-2007 & $18+$ & 47.6 & 58.6 & 4,340 & 1,986 & 68.4 & 68 & 3.3 \\
\hline Portugal & 2008-2009 & $18+$ & 45.3 & 63.2 & 3,849 & 2,060 & 57.3 & 145 & 7.2 \\
\hline Romania & 2005-2006 & $18+$ & 50.5 & 53.7 & 2,357 & 2,357 & 70.9 & 101 & 3.6 \\
\hline Poland & 2010-2011 & $18-64$ & 40.6 & 55.0 & 10,081 & 4,000 & 50.4 & 159 & 3.6 \\
\hline \multicolumn{10}{|l|}{ Middle East } \\
\hline Israel & 2002-2004 & $21+$ & 45.8 & 51.0 & 4,859 & 4,859 & 72.6 & 410 & 7.8 \\
\hline Iraq & 2006-2007 & $18+$ & 37.4 & 51.7 & 4,332 & 4,332 & 95.2 & 165 & 4.0 \\
\hline Weighted average response rate $(\%)$ & & & & & & & 78.0 & & \\
\hline Total sample size $(n)$ & & & & & 98,714 & 52,095 & & 2,580 & \\
\hline
\end{tabular}

question they were classified as having a history of diabetes for these analyses. Respondents were also asked how old they were when they were first diagnosed with diabetes. This year is referred to herein as the age of onset of diabetes, although it is recognised that the underlying pathology develops over many years and that it is possible to have diabetes before it is detected. Only adult-onset diabetes (onset age 21+ years) was investigated in this paper. As a sensitivity analysis, we restricted the age of onset to a minimum of 30 years to further reduce the risk of including individuals with type I diabetes.

Statistical analysis Although the data collection was crosssectional, there was a time element in the data as we asked for the time of onset of diabetes and mental disorders. Essentially, we analysed the associations between mental disorder and diabetes by using this time-related information. We only wanted to consider associations between temporally preexisting mental disorders and diabetes, excluding episodes of mental disorders that occurred in the same year as diabetes diagnosis, or following diabetes. It is only by using survival analysis that we are able to exclude such episodes from the predictor set because the data are organised in person-year files. Comparable with previous studies using these data [26, 27], we used discrete-time survival analyses [28] with personyear as the unit of analysis to test associations between first onset of mental disorders and diabetes diagnosis. For these analyses, a person-year dataset was created in which each year in the life of each respondent up to and including the age of onset of diabetes or their age at interview (whichever came first) was treated as a separate observational record, with the year of diabetes onset coded 1 and earlier years coded 0 on a dichotomous outcome variable. Persons who reported diabetes onset before age 21 years $(n=192)$ were excluded from analysis. Mental disorder predictors were coded 1 from the year after first onset of each individual mental disorder. This time lag of 1 year in the coding of the predictors ensured that in cases where the first onset of a mental disorder and of diabetes occurred in the same year, the mental disorder would not count as a predictor. Only person-years up to the diagnosis of diabetes were analysed so that only mental disorder episodes occurring before the onset of diabetes were included in the predictor set. Logistic regression analysis was used to 
analyse these data with the survival coefficients presented as ORs, indicating the relative odds of diabetes diagnosis in a given year for a person with a history of mental disorder compared with a person without that mental disorder (for details, see electronic supplementary material [ESM] Methods).

A series of bivariate and multivariable models were developed including the predictor mental disorder plus control variables. Models control for person-years, country, sex, current age and, in the multivariable models, other mental disorders. Bivariate models investigated the association of specific mental disorders with subsequent diabetes onset. The next model, a multivariable model, estimated the association of each mental disorder with diabetes onset adjusting for mental disorder comorbidity. Our approach was to not control for covariates that could be on the causal pathway between mental disorders and subsequent diabetes as our design does not allow us to distinguish between confounders, mediators and consequences. We did not split results for men and women as we did not find significant interaction effects between sex and most of the psychiatric disorders. The proportionality assumption was checked by including time-dependent covariates in the model (i.e. interactions of each of the predictors [mental disorders] with time [personyear] in predicting diabetes diagnosis). We did this for each predictor individually. Only three of the 16 predictors showed significant interactions with person-years (depression, social phobia and generalised anxiety disorder). The interactions were further explored and interpreted as chance findings.

Our earlier studies of concurrent mental-physical comorbidity in the WMH surveys found that these associations were generally consistent across nations, despite varying prevalence of mental disorders and physical conditions [15, 29]. All analyses for this paper were therefore run on the pooled cross-national dataset. As the WMH data are both clustered and weighted, the design-based Taylor series linearisation [30] implemented in version 10 of the SUDAAN software system (RTI International, Research Triangle Park, NC, USA) was used to estimate standard errors and evaluate the statistical significance of coefficients. Given the number of tests, we set statistical significance at $p<0.01$.

\section{Results}

Descriptives The survey characteristics are shown in Table 1, together with information about the number of survey respondents reporting a history of diabetes $(n=2,580)$, representing a total of $2,161,945$ person-years. The mean age of adult diabetes onset was 50.3 years (median 49.8). There were 395 cases with a reported diagnosis of diabetes under 30 years of age and 2,377 at or after 30 years of age.

Mental disorders as predictors of diabetes onset Table 2 shows the prevalence rates of mental disorders for the total sample $(n=52,095)$ and persons reporting diabetes $(n=2,580)$. Within this subsample we identified those mental disorders with an onset before diabetes. The highest prevalence rates were found for major depression $(11.3 \%)$, specific phobia $(7.0 \%)$ and alcohol abuse (5.8\%). The mean age of onset of mental disorders ranged from 9.3 to 31.6 years, with the lowest mean onset age for specific phobia (9.3 years), social phobia (13.7 years), and bulimia nervosa (15.6 years).

The associations between individual mental disorders and diabetes diagnosis were first investigated in a series of bivariate models (i.e. only one mental disorder considered at a time). The data presented in Table 3 show that all mental disorders were associated with diabetes except for obsessivecompulsive disorder, with ORs in the range 1.3-3.9. The two eating disorders, binge eating disorder and bulimia nervosa, stand out as having a particularly strong association with diabetes (OR 3.8 and 3.9, respectively).

To investigate the possibility that comorbidity among mental disorders plays a role in the associations with diabetes onset, we first examined the levels of comorbidity in individuals that would develop diabetes (Table 4). All mental disorders were significantly associated with each other, with some exceptions: agoraphobia and panic, alcohol abuse and alcohol dependence, drug abuse and drug dependence. These disorders are by definition mutually exclusive, explaining the lack of correlations. In addition, no significant associations were found between obsessive-compulsive disorder and alcohol and drug abuse. For the rest, all mental disorders were substantially associated, with ORs as high as 66.4 for alcohol dependence and drug dependence and 37.8 for binge eating disorder and bulimia nervosa. Most of the remaining ORs were in the range of 5-10, indicating high levels of comorbidity.

When lifetime comorbidity until the age of diabetes onset was taken into account in the multivariable models, the magnitude of associations diminished substantially for most of the disorders, rendering the associations significant only for 4 out of 16: major depressive episode/dysthymia, intermittent explosive disorder, binge eating disorder and bulimia nervosa (Table 5).

The test of the global null hypothesis - as to whether any of the set of predictors coefficients is not equal to zero-was significant $\left(\chi^{2}=114.7, p \leq 0.01\right)$ and the test for significant difference between ORs indicates that we can reject the hypothesis that the ORs are the same for all mental disorders $\left(\chi^{2}=32.2, p \leq 0.01\right)$. The sensitivity analysis, in which we restricted age of onset of diabetes to a minimum of 30 years, resulted in highly similar findings (see ESM Tables 1 and 2).

\section{Discussion}

This is the first study evaluating the associations of a wide range of DSM-IV mental disorders with diabetes diagnosis in 
Table 2 Lifetime prevalence and age of onset of the 16 mental disorders

\begin{tabular}{|c|c|c|c|c|c|c|c|c|}
\hline & \multirow{2}{*}{\multicolumn{2}{|c|}{$\begin{array}{l}\text { Total sample } \\
(N=52,095) \\
\text { Prevalence }\end{array}$}} & \multirow{2}{*}{\multicolumn{2}{|c|}{$\begin{array}{l}\text { Subjects with adult-onset } \\
\text { diabetes }(n=2,580) \\
\text { Prevalence }\end{array}$}} & \multicolumn{4}{|c|}{$\begin{array}{l}\text { Subjects with adult-onset diabetes }(n=2,580) \text { and } \\
\text { mental disorders with onset prior to diabetes }\end{array}$} \\
\hline & & & & & \multicolumn{2}{|c|}{ Prevalence } & \multicolumn{2}{|c|}{ Age of onset } \\
\hline & $\%$ & SE & $\%$ & SE & $\%$ & SE & Mean & SE \\
\hline Major depressive episode/dysthymia & 12.6 & 0.2 & 14.8 & 0.7 & 11.3 & 0.7 & 31.6 & 0.8 \\
\hline Bipolar disorder (broad) & 1.9 & 0.1 & 1.7 & 0.2 & 1.2 & 0.2 & 25.0 & 1.9 \\
\hline Panic disorder & 1.8 & 0.1 & 2.3 & 0.3 & 1.8 & 0.3 & 25.6 & 2.0 \\
\hline Generalised anxiety disorder & 4.2 & 0.1 & 5.8 & 0.5 & 3.9 & 0.4 & 28.7 & 1.3 \\
\hline Social phobia & 4.4 & 0.1 & 4.2 & 0.4 & 4.1 & 0.4 & 13.7 & 1.0 \\
\hline Specific phobia & 7.3 & 0.1 & 7.3 & 0.6 & 7.0 & 0.6 & 9.3 & 0.6 \\
\hline Agoraphobia without panic & 0.9 & 0.0 & 1.0 & 0.2 & 0.9 & 0.2 & 18.7 & 1.9 \\
\hline Post-traumatic stress disorder & 3.3 & 0.1 & 4.5 & 0.5 & 3.3 & 0.5 & 28.7 & 1.9 \\
\hline Obsessive-compulsive disorder & 1.3 & 0.1 & 0.7 & 0.2 & 0.6 & 0.2 & 17.1 & 2.5 \\
\hline Intermittent explosive disorder & 2.1 & 0.1 & 1.9 & 0.3 & 1.8 & 0.3 & 19.7 & 1.7 \\
\hline Binge eating disorder & 0.7 & 0.0 & 1.0 & 0.2 & 0.9 & 0.2 & 25.8 & 2.9 \\
\hline Bulimia nervosa & 0.4 & 0.0 & 0.6 & 0.2 & 0.5 & 0.2 & 15.6 & 1.9 \\
\hline Alcohol abuse & 7.4 & 0.1 & 6.2 & 0.5 & 5.8 & 0.5 & 24.1 & 0.8 \\
\hline Alcohol dependence with abuse & 2.1 & 0.1 & 2.2 & 0.3 & 2.1 & 0.3 & 24.6 & 1.5 \\
\hline Drug abuse & 2.5 & 0.1 & 1.8 & 0.3 & 1.8 & 0.3 & 21.0 & 0.7 \\
\hline Drug dependence with abuse & 0.9 & 0.0 & 0.9 & 0.2 & 0.9 & 0.2 & 21.7 & 1.0 \\
\hline
\end{tabular}

an international sample. The inclusion of a wide range of disorders and the large sample size enabled us to reliably adjust for mental disorder comorbidity and thus estimate the

Table 3 Bivariate associations (ORs) between DSM-IV mental disorders and the subsequent diagnosis of diabetes ${ }^{\mathrm{a}}$

\begin{tabular}{llr}
\hline Disorder & OR $(95 \%$ CI $)$ & $p$ value \\
\hline Major depressive episode/dysthymia & $1.4(1.3,1.7)$ & $<0.001$ \\
Bipolar disorder (broad) & $1.7(1.2,2.3)$ & 0.001 \\
Panic disorder & $1.6(1.2,2.2)$ & 0.002 \\
Generalised anxiety disorder & $1.3(1.1,1.7)$ & 0.009 \\
Social phobia & $1.4(1.1,1.7)$ & 0.008 \\
Specific phobia & $1.4(1.1,1.6)$ & 0.001 \\
Agoraphobia without panic & $1.5(1.0,2.1)$ & 0.043 \\
Post-traumatic stress disorder & $1.5(1.1,2.0)$ & 0.012 \\
Obsessive-compulsive disorder & $1.4(0.7,2.6)$ & 0.388 \\
Intermittent explosive disorder & $1.9(1.4,2.6)$ & $<0.001$ \\
Binge eating disorder & $3.8(2.2,6.5)$ & $<0.001$ \\
Bulimia nervosa & $3.9(2.2,7.1)$ & $<0.001$ \\
Alcohol abuse & $1.3(1.1,1.6)$ & 0.008 \\
Alcohol dependence with abuse & $1.6(1.2,2.2)$ & 0.001 \\
Drug abuse & $2.0(1.4,2.8)$ & $<0.001$ \\
Drug dependence with abuse & $2.9(1.8,4.7)$ & $<0.001$ \\
\hline
\end{tabular}

${ }^{a}$ Each mental disorder type was estimated as a predictor of the physical condition onset in a separate discrete-time survival model controlling for age cohorts, sex, person-year and country unique association of each of the mental disorders with diabetes. Our main findings were that in unadjusted models virtually all included mental disorders were associated with diabetes and that controlling for mental comorbidity resulted in significant associations only for depression and impulse control disorders (intermittent explosive disorder and eating disorders in particular). The magnitude of the association between depression and diabetes diagnosis was about $40 \%$ increased risk in unadjusted analyses and 30\% in adjusted analyses. These findings are in concordance with results from previous meta-analyses (37-56\% unadjusted) $[9,31]$ and a recent report using insurance claims data (43\% unadjusted) [32], and suggest that the association between depression and diabetes is relatively independent from other psychiatric disorders. The association between impulse disorders and diabetes diagnosis has not been reported before. By far the strongest prospective associations were found with respect to eating disorders and diabetes. From a mechanistic point of view, this association seems to point to the importance of glucose dysregulation and obesity-associated eating disorders, which may eventually result in later diabetes [33,34]. However, based on the associations between impulse control disorders, including intermittent explosive disorders, and diabetes, at least two other candidate mechanisms may be suggested, namely low levels of HDL-cholesterol and decreased serotonin functioning, both of which have been associated with aggression and diabetes $[35,36]$. It should be noted that these processes may be already present early in life and may manifest differently 


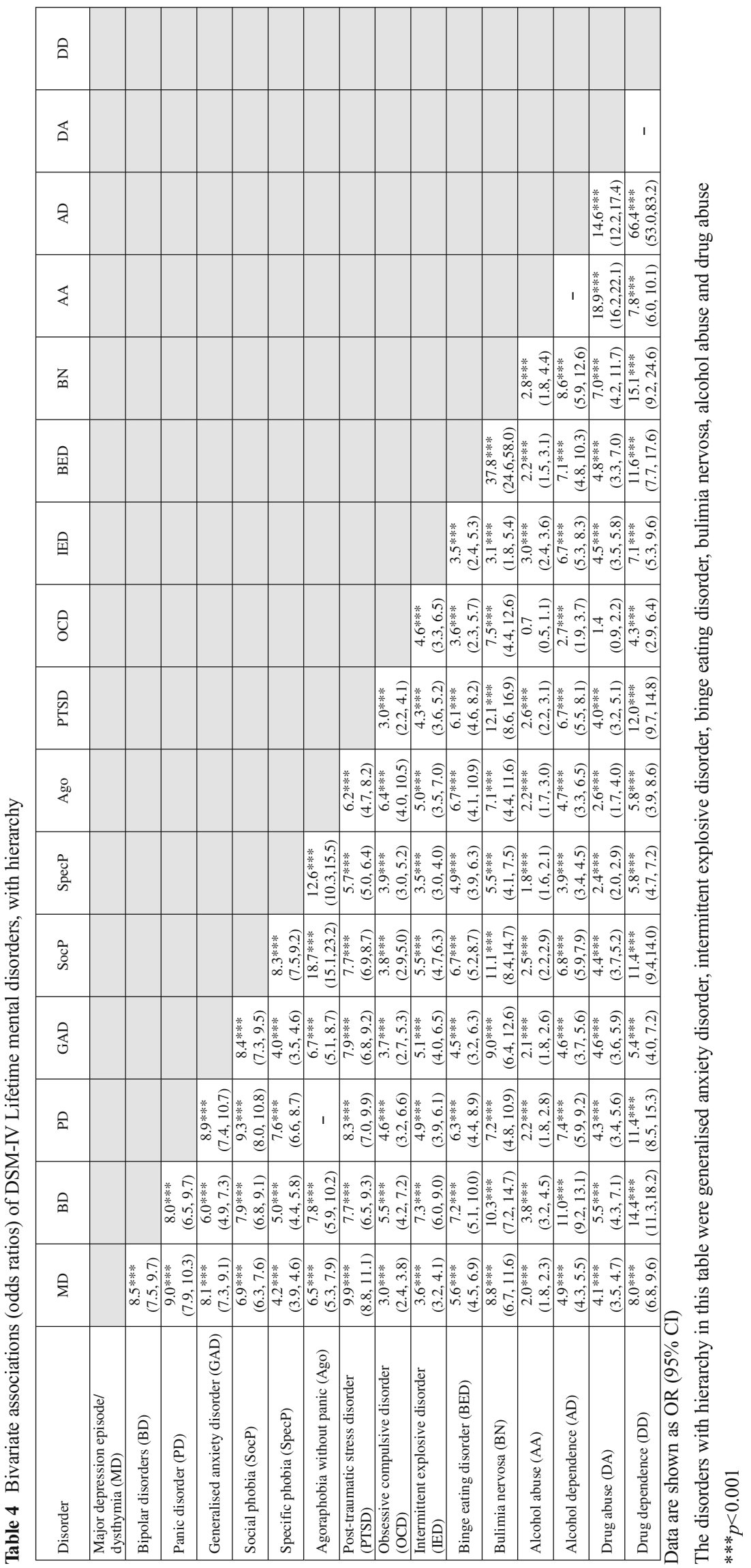


Table 5 Multivariable associations (ORs) between DSM-IV mental disorders and the subsequent diagnosis of diabetes ${ }^{\mathrm{a}}$

\begin{tabular}{llr}
\hline Disorder & OR $(95 \%$ C.I. $)$ & $p$ value \\
\hline Major depressive episode/dysthymia & $1.3(1.1,1.5)$ & 0.002 \\
Bipolar disorder (broad) & $1.2(0.8,1.6)$ & 0.392 \\
Panic disorder & $1.2(0.9,1.7)$ & 0.174 \\
Generalised anxiety disorder & $1.0(0.8,1.3)$ & 0.971 \\
Social phobia & $1.1(0.8,1.3)$ & 0.714 \\
Specific phobia & $1.2(1.0,1.4)$ & 0.104 \\
Agoraphobia without panic & $1.1(0.8,1.7)$ & 0.532 \\
Post-traumatic stress disorder & $1.1(0.8,1.6)$ & 0.445 \\
Obsessive-compulsive disorder & $1.1(0.6,2.1)$ & 0.785 \\
Intermittent explosive disorder & $1.6(1.1,2.1)$ & 0.007 \\
Binge eating disorder & $2.6(1.7,4.0)$ & $<0.001$ \\
Bulimia nervosa & $2.1(1.3,3.4)$ & 0.003 \\
Alcohol abuse & $1.0(0.8,1.4)$ & 0.760 \\
Alcohol dependence with abuse & $1.1(0.8,1.6)$ & 0.583 \\
Drug abuse & $1.2(0.8,1.8)$ & 0.294 \\
Drug dependence with abuse & $1.5(0.9,2.5)$ & 0.167 \\
\hline
\end{tabular}

${ }^{a}$ The model was estimated with dummy variables for all mental disorders entered simultaneously, including adjustment for age cohorts, sex, person-year and country

during the life course. For instance, a child with disturbed serotonin functioning may be characterised by poor impulse control and problematical eating behaviour early in life and by obesity and diabetes later in life, perhaps accompanied by depression. Unfortunately with the present data, we are not able to evaluate this in more detail and can only speculate.

The vast majority of studies investigating the associations of mental disorders with diabetes has been restricted to depression. Our current findings stress that depression indeed seems to have an independent association with diabetes onset, as controlling for mental comorbidity only moderately affected the association between depression and diabetes. However, our analyses did signal that impulse control disorders are also important. It should be kept in mind, however, that their prevalence rates are considerably lower than that of depression (i.e. $0.9 \%$ for binge eating disorder, $0.5 \%$ for bulimia nervosa and $1.8 \%$ for intermittent explosive disorder compared with $11.3 \%$ for depression). Of interest, impulse control disorders have a typical age of onset at around 20 years of age, which is generally earlier than the age of onset for most of the other mental disorders that were considered in this study, including depression. Indeed, in our sample we found that specifically bulimia nervosa had a relatively early age of onset (15.6 years). Perhaps further studies could evaluate the possibility that impulse control disorders, including eating disorders and intermittent explosive disorder, may serve as risk factors for depression and diabetes, or that these disorders are expressions of an underlying pathology that might lead to diabetes. The fact that in particular these four disorders remained associated with diabetes is also compatible with a hypothesis in which these disorders represent relatively independent risk factors for diabetes.

The results of this study should be considered within the context of the following strengths and limitations. The retrospective assessment of mental disorders is likely to have resulted in under-reporting of some mental disorders and inaccuracies in the age of onset timing. A second key limitation is the self-report of diabetes. Although self-reports of medically diagnosed diabetes have been shown to have good validity $[37,38]$, it is possible that we have missed cases of diabetes (particularly undetected type 2 diabetes), which may have differed across the included countries. Both limitations will probably have resulted in largely non-differential misclassification of individuals with regard to the predictor and outcome in this study. This will have the effect of weakening the strength of the reported associations between mental disorders and diabetes, making the results we report here conservative. However, there may also be forms of differential misclassification leading to biased estimates of variables. For instance, it is possible that persons with a mental disorder have a decreased access to healthcare, which would reduce the risk of diabetes being diagnosed. A further limitation is that as this study was only conducted among diabetes (and mental disorder) survivors some of those most affected by an association between mental disorder and diabetes are not included in the sample due to premature mortality. In addition, it should be noted that although we used a large international sample of respondents, we did not stratify per country or culture. Stratifying by country would have led to insufficient numbers of subjects with which to conduct the multivariable models, while stratifying for culture would result in rather arbitrary decisions in classifying countries. We did control for country as a confounder, which we think is an advantage over the existing literature, which largely focuses on single countrybased studies. A further limitation of the present study is that we were not able to differentiate between type 1 and type 2 diabetes. Although the majority of cases will be type 2 diabetes, and this is strengthened by the fact that we included only diabetes cases with an adult onset and found similar results when heightening the age of onset to a minimum of 30 years, some of the cases might be type 1 diabetes. In addition, it should be noted that although the aetiology of type 1 and type 2 diabetes is markedly different, the associations with depression appear to be rather comparable. In a recent meta-analysis [39] it was concluded that the risk of depression associated with diabetes mainly depends on whether diabetes is detected or remains undiagnosed. However, it remains unclear whether the same argument would hold with respect to eating disorders and diabetes onset. Further studies should therefore try to clarify whether our present findings are different for patients 
with type 1 and type 2 diabetes. We were not able to include all mental disorders in our analyses and therefore were not able to present a complete picture. Specifically, in a large-scale population-based study such as the WMH surveys it is not possible to include the diagnosis of schizophrenia because the interviewer would require specific clinical skills to rule out false-positive cases. The CIDI interview is conducted by trained laypersons, and therefore does not cover schizophrenia. This is unfortunate as the literature suggests a role for several metabolism-related hormones in schizophrenia that are also be related to diabetes [40, 41]. Furthermore, there are indications that shared susceptibility genes may link the two [42], and there are also potential effects of antipsychotic medication that are relevant to diabetes onset [43]. As a final limitation, we can only speculate regarding the mechanisms that may be involved in the associations found. This study did not aim to explain the associations but rather documented them in a large population-based sample that was less biased than the existing registry studies.

In conclusion, we found that in bivariate analyses almost all mental disorders had associations with diabetes. Most of these associations were attributable to psychiatric comorbidity and specific associations of depression and eating disorders with diabetes. Our findings thus suggest that the focus on depression in the context of diabetes prediction is warranted, but may be extended to impulse control disorders.

Acknowledgements We thank the staff of the WMH Data Collection and Data Analysis Coordination Centres for assistance with instrumentation, fieldwork and consultation on data analysis. A complete list of all within-country and cross-national WMH publications can be found at www.hcp.med.harvard.edu/wmh/ (accessed 13 December 2013).

Funding The WHO World Mental Health (WMH) Survey Initiative is supported by the National Institute of Mental Health (NIMH; R01 MH070884), the John D. and Catherine T. MacArthur Foundation, the Pfizer Foundation, the US Public Health Service (R13-MH066849, R01MH069864 and R01 DA016558), the Fogarty International Center (FIRCA R03-TW006481), the Pan American Health Organization, Eli Lilly, OrthoMcNeil Pharmaceutical, GlaxoSmithKline and Bristol-Myers Squibb. The Colombian National Study of Mental Health (NSMH) was supported by the Ministry of Social Protection, with supplemental support from the Saldarriaga Concha Foundation. The European surveys were funded by the European Commission (Contracts QLG5-1999-01042, SANCO 2004123 and EAHC 20081308), the Piedmont Region (Italy), Fondo de Investigación Sanitaria, Instituto de Salud Carlos III, Spain (FIS 00/0028), Ministerio de Ciencia y Tecnología, Spain (SAF 2000-158-CE), Departament de Salut, Generalitat de Catalunya, Spain, Instituto de Salud Carlos III (CIBER CB06/02/0046, RETICS RD06/0011 REM-TAP) and other local agencies and by an unrestricted educational grant from GlaxoSmithKline. The World Mental Health Japan (WMHJ) survey was supported by a Grant for Research on Psychiatric and Neurological Diseases and Mental Health (H13-SHOGAI-023, H14-TOKUBETSU-026 and H16KOKORO-013) from the Japan Ministry of Health, Labour and Welfare. The Mexican National Comorbidity Survey (MNCS) was supported by the National Institute of Psychiatry Ramon de la Fuente (INPRFMDIES 4280) and by the National Council on Science and Technology (CONACyTG30544- H), with supplemental support from the PanAmerican Health Organization (PAHO). The Peruvian World Mental Health Study was funded by the National Institute of Health of the Ministry of Health of Peru. The Polish project Epidemiology of Mental Health and Access to Care EZOP Poland was carried out by the Institute of Psychiatry and Neurology in Warsaw in consortium with Department of Psychiatry - Medical University in Wroclaw and National Institute of Public Health - National Institute of Hygiene in Warsaw and in partnership with Psykiatrist Institut Vinderen Universitet, Oslo. The project was funded by the Norwegian Financial Mechanism and the European Economic Area Mechanism as well as Polish Ministry of Health. No support from the pharmaceutical industry or other commercial sources was received. The Shenzhen Mental Health Survey is supported by the Shenzhen Bureau of Health and the Shenzhen Bureau of Science, Technology, and Information. Implementation of the Iraq Mental Health Survey (IMHS) and data entry were carried out by the staff of the Iraqi MOH and MOP with direct support from the Iraqi IMHS team, with funding from both the Japanese and European Funds through United Nations Development Group Iraq Trust Fund (UNDG ITF). The Israel National Health Survey is funded by the Ministry of Health with support from the Israel National Institute for Health Policy and Health Services Research and the National Insurance Institute of Israel. Te Rau Hinengaro: The New Zealand Mental Health Survey (NZMHS) was supported by the New Zealand Ministry of Health, Alcohol Advisory Council and the Health Research Council. The Portuguese Mental Health Study was carried out by the Department of Mental Health, Faculty of Medical Sciences, NOVA University of Lisbon, with collaboration of the Portuguese Catholic University, and was funded by Champalimaud Foundation, Gulbenkian Foundation, Foundation for Science and Technology (FCT) and Ministry of Health. The Romania WMH study projects 'Policies in Mental Health Area' and 'National Study regarding Mental Health and Services Use' were carried out by National School of Public Health \& Health Services Management (former National Institute for Research and Development in Health, present National School of Public Health Management and Professional Development, Bucharest), with technical support from Metro Media Transilvania, the National Institute of Statistics - National Centre for Training in Statistics, SC Cheyenne Services SRL, Statistics Netherlands and were funded by Ministry of Public Health (former Ministry of Health) with supplemental support of Eli Lilly Romania SRL. The US National Comorbidity Survey Replication (NCS-R) is supported by the National Institute of Mental Health (NIMH; U01-MH60220) with supplemental support from the National Institute of Drug Abuse (NIDA), the Substance Abuse and Mental Health Services Administration (SAMHSA), the Robert Wood Johnson Foundation (RWJF; Grant 044708) and the John W. Alden Trust.

Work on this paper was funded by a grant from the Health Research Council of New Zealand to KMS.

Duality of interest JMH has been advisor or participated in advisory boards of Eli Lilly, Lundbeck and Roche. J-PL has served on speaker bureaus for Servier, Pfizer-Wyeth, Sanofi and Pierre Fabre. RCK has been a consultant for AstraZeneca, Analysis Group, Bristol-Myers Squibb, Cerner-Galt Associates, Eli Lilly, GlaxoSmithKline, HealthCore, Health Dialog, Roche, Integrated Benefits Institute, John Snow, Kaiser Permanente, Matria, Mensante, Merck, Ortho-McNeil Janssen Scientific Affairs, Pfizer, Primary Care Network, Research Triangle Institute, Sanofi-Aventis, Shire US, SRA International, Takeda Global Research and Development, Transcept Pharmaceuticalsand Wyeth-Ayerst.

RCK has served on advisory boards for Appliance Computing II, Eli Lilly, Mindsite, Ortho-McNeil Janssen Scientific Affairs, Johnson \& Johnson, Plus One Health Management and Wyeth-Ayerst. RCK has received research support for his epidemiological studies from Analysis Group, Bristol-Myers Squibb, Eli Lilly, EPI-Q, GlaxoSmithKline, Johnson \& Johnson, Ortho-McNeil Janssen Scientific Affairs, Pfizer, SanofiAventis, Shire US and Walgreens. RCK owns a 25\% share in DataStat.

All other authors declare that there is no duality of interest associated with their contribution to this manuscript.

The funders had no input into the design and conduct of the study, collection, management, analysis and interpretation of the data, or preparation, review or approval of the manuscript. 
Contribution statement $\mathrm{PdJ}$ drafted the paper and takes responsibility for the work as a whole, including the decision to submit and publish the manuscript. PdJ and KMS designed the study. CCWL carried out the statistical analyses under the direction of KMS. KMS takes responsibility for the integrity of the data analysis. All authors were involved in data collection, participated in drafting the manuscript and approved its final version.

\section{References}

1. Anderson RJ, Freedland KE, Clouse RE, Lustman PJ (2001) The prevalence of comorbid depression in adults with type 2 diabetes: a systematic review and meta-analysis. Diabetes Care 24:1069-1078

2. Mezuk B, Alsbrecht S, Eaton WW, Golden SH (2008) Depression and type 2 diabetes over the lifespan. Diabetes Care 31:2383-2390

3. Nouwen A, Winkley K, Twisk J et al (2010) Type 2 diabetes mellitus as a risk factor for the onset of depression: a systematic review and meta-anlysis. Diabetologia 53:2480-2486

4. Ali S, Stone MA, Peters JL, Davies MJ, Khunti K (2006) The prevalence of co-morbid depression in adults with type 2 diabetes: a systematic review and meta-analysis. Diabet Med 23:1165-1173

5. Black SA, Markides KS, Ray LA (2003) Depression predicts increased incidence of adverse health outcomes in older Mexican Americans with type 2 diabetes. Diabetes Care 26: 2822-2828

6. Bruce DG, Davis WA, Starkstein SE, Davis TM (2005) A prospective study of depression and mortality in patients with type 2 diabetes: the Fremantle Diabetes Study. Diabetologia 48:2532-2539

7. Egede LE, Nietert PJ, Zheng D (2005) Depression and all-cause and coronary heart disease mortality among adults with and without diabetes. Diabetes Care 28:1339-1345

8. de Groot M, Anderson RJ, Freedland KE, Clouse RE, Lustman PJ (2001) Association of depression and diabetes complications: a metaanalysis. Psychosom Med 63:619-630

9. Knol MJ, Twisk J, Beekman AT, Heine RJ, Snoek FJ, Pouwer F (2006) Depression as a risk factor for the onset of type 2 diabetes: a meta-analysis. Diabetologia 49:837-845

10. Bromet E, Andrade LH, Hwang I et al (2011) Cross-national epidemiology of DSM-IV major depressive episode. BMC Med 9:90

11. Koopman RJ, Mainous AG 3rd, Diaz VA, Geesey ME (2005) Changes in age at diagnosis of type 2 diabetes mellitus in the United States, 1998 to 2000. Ann Fam Med 3:60-63

12. Musselman DL, Betan E, Larsen H, Philips LS (2003) Relationship of depression to diabetes types 1 and 2: epidemiology, biology and treatment. Biol Psychiatry 54:317-329

13. Golden SH, Lazo M, Carnethon M et al (2008) Examining a bidirectional association between depressive symptoms and diabetes. JAMA 299:2751-2759

14. Kiecolt-Glaser JK, McGuire L, Robles TF, Glaser R (2002) Emotions, morbidity, and mortality: new perspectives from psychoneuroendocrinology. Annu Rev Psychol 53:83-107

15. Lin EH, von Korf M, WMH Survey Consortium (2008) Mental disorders among persons with diabetes- results from the world mental health surveys. J Psychosom Res 65:571-580

16. Lloyd CE, Roy T, Nouwen A, Chauhan AM (2012) Epidemiology of depression in diabetes: international and cross-national issues. J Affect Disord 142:S22-S29

17. Egede LE, Ellis C (2010) Diabetes and depression: global perspectives. Diabetes Res Clin Pract 87:302-312

18. Smink FRE, van Hoeken D, Hoek HW (2012) Epidemiology of eating disorders: incidence, prevalence and mortality rates. Curr Psychiatr Rep 14:406-414
19. Herzog DB, Keller MB, Sacks NR, Yeh CJ, Lavori PW (1992) Psychiatric comorbidity in treatment-seeking anorexics and bulimics. J Am Acad Child Adolesc Psychiatry 31:810-818

20. Boschloo L, Vogelzangs N, Smit JH et al (2011) Comorbidity and risk indicators for alcohol use disorders among persons with anxiety and/or depressive disorders: findings from the Netherlands Study of Depression and Anxiety. J Affect Disord 131:233-242

21. American Psychiatric Association Workgroup on Eating Disorders (2006) Practice guidelines for the treatment of patients with eating disorders (revision). Am J Psychiatry 163:1-39

22. Godart NT, Perdereau F, Rein Z et al (2007) Comorbidity studies of eating disorders and mood disorders. Critical review of the literature. J Affect Disord 97:37-49

23. Kessler RC, Ustun B (2004) The World Mental Health (WMH) Survey Initiative version of the World Health Organization (WHO) Composite International Diagnostic Interview (CIDI). Int J Methods Psychiatr Res 13:93-121

24. Kessler RC, Ustun TB (2008) The WHO World Mental Health Surveys: global perspectives on the epidemiology of mental disorders. Cambridge University Press, New York

25. Haro JM, Arbabzadeh-Bouchez S, Brugha TS et al (2006) Concordance of the Composite International Diagnostic Interview Version 3.0 (CIDI 3.0) with standardized clinical assessments in the WHO World Mental Health Surveys. Int J Methods Psychiatr Res 15:167-180

26. Scott KM, de Jonge P, Alonso J et al (2013) Associations between DSM-IV mental disorders and subsequent heart disease onset: beyond depression. Int J Cardiol 168:5293-5299

27. Scott KM, Alonso J, de Jonge P et al (2013) Associations between DSM-IV mental disorders and onset of self-reported peptic ulcer in the World Mental Health Surveys. J Psychosom Res $75: 121-127$

28. Singer JD, Willett JB (1993) It's about time: using discrete-time survival analysis to study duration and the timing of events. J Educ Stat 18:155-195

29. Von Korff MR, Scott KM, Gureje O (2009) Global perspectives on mental-physical comorbidity in the WHO World Mental Health Surveys. Cambridge University Press, New York

30. Shah BV (1998) Linearization methods of variance estimation. In: Armitage P, Colton T (eds) Encyclopedia of biostatistics. Wiley, Chichester, pp 2276-2279

31. Rotella F, Manuzzi E (2013) Depression as a risk factor for diabetes: a meta-analysis of longitudinal studies. J Clin Psychiatry 74:31-37

32. Chen PC, Chan YT, Chen HF, Ko MC, Li CY (2013) Populationbased cohort analyses of the bidirectional relationship between type 2 diabetes and depression. Diabetes Care 36:376-382

33. Scott KM, McGee MA, Wells JE, Oakley Brown MA (2008) Obesity and mental disorders in the adult general population. J Psychosom Res 64:97-105

34. Luppino FS, de Wit LM, Bouvy PF et al (2010) Overweight, obesity, and depression: a systematic review and meta-analysis of longitudinal studies. Arch Gen Psychiatry 67:220-229

35. Buydens-Branchey L, Branchey M, Hudson J, Fergeson P (2000) Low HDL cholesterol, aggression and altered central serotonergic activity. Psychiatry Res 93:93-102

36. Duke AA, Bègue L, Bell R, Eisenlohr-Moul T (2013) Revisiting the serotonin-aggression relation in humans: a meta-analysis. Psychol Bull 139:1148-1172

37. Kriegsman DM, Penninx BW, van Eijk JT, Boeke AJ, Deeg DJ (1996) Self-reports and general practitioner information on the presence of chronic diseases in community dwelling elderly. J Clin Epidemiol 49:1407-1417

38. Baumeister H, Kriston L, Bengel J, Harter M (2010) High agreement of self-report and physician-diagnosed somatic conditions yields limited bias in examining mental-physical comorbidity. $\mathrm{J}$ Clin Epidemiol 63:558-565 
39. Nouwen A, Nefs G, Caramlau I et al (2011) Prevalence of depression in individuals with impaired glucose metabolism or undiagnosed diabetes: a systematic review and meta-analysis of the European Depression in Diabetes (EDID) Research Consortium. Diabetes Care 34:752-762

40. Harris LW, Guest PC, Wayland MT et al (2013) Schizophrenia: metabolic aspects of aetiology, diagnosis and future treatment strategies. Psychoneuroendocrinology 38:752-766

41. Guest PC, Schwartz E, Krishnamurthy D et al (2011) Altered levels of circulating insulin and other neuroendocrine hormones associated with the onset of schiohphrenia. Psychoneuroendocrinology 36: 1092-1096

42. Liu Y, Li Z, Zhang M, Deng Y, Yi Z, Shi T (2013) Exploring the pathogenetic association between schizophrenia and type 2 diabetes mellitus diseases based on pathway analysis. BMC Med Genomics 6(Suppl 1):S17

43. Peet M (2004) International variations in the outcome of schizophrenia and the prevalence of depression in relation to national dietary practices: an ecological analysis. Br J Psychiatry 184: 404-408 